\title{
Possibilidades de mediação dos espaços nas brincadeiras e aprendizagens das crianças na educação infantil
}

\author{
Kellen Fabiana Sitta \\ Universidade Federal de São Carlos, SP - Brasil. \\ kellen.sitta@gmail.com \\ Maria Aparecida Mello \\ Universidade Federal de São Carlos, SP - Brasil. \\ mmello@ufscar.br
}

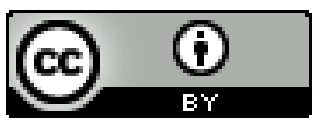

Educação: teoria e prática, Rio Claro, SP, Brasil - elSSN: 1981-8106

Está licenciada sob Licença Creative Common

\begin{abstract}
Resumo
Este artigo discute o espaço físico das escolas de Educação Infantil como mediador no processo de aprendizagem e desenvolvimento infantis, tendo como questão de pesquisa: de que maneira os espaços das escolas de Educação Infantil podem ser mediadores das aprendizagens das crianças? Os objetivos foram: discutir a organização dos espaços internos e externos de escolas de Educação Infantil; averiguar quais desses espaços são destinados às brincadeiras das crianças; identificar como são organizados e analisar as possibilidades de mediação desses espaços nas aprendizagens e brincadeiras das crianças. A metodologia envolveu questionários com 60 professores e 27 diretoras de escolas de Educação Infantil. Realizamos observações em duas escolas, registradas em diário de campo e fotografia. Os resultados demonstram elementos positivos e negativos da organização e utilização dos espaços físicos nas escolas. Seu aspecto mediador nas aprendizagens das crianças pode passar despercebido para as professoras, se a reflexão sobre a sua qualidade não for relacionada ao objetivo da atividade para a criança. A mediação dos espaços nas aprendizagens das crianças precisa fazer parte das preocupações de professores, gestores, arquitetos, engenheiros e foco de políticas públicas.
\end{abstract}

Palavras-Chave: Educação Infantil. Teoria Histórico-Cultural. Brincadeira. Espaço físico.

\section{Possibilities about the mediation of the spaces in the children's play and learning in the early childhood education}




\begin{abstract}
This paper discusses the physical space of Early Childhood Education schools as mediator in the children's learning and development process, and having research question: of which forms the spaces of the Early Childhood Education schools can be mediators of the children's learning? The goals was: to discuss the organization of the internal e external spaces of the Early Childhood Education schools; to investigate which those spaces are intended to the children's plays; identify how are organized and analyze the possibilities of mediation this spaces in the children's learning and plays. The methodology envolved questionnaires with 60 teachers and 27 manageress of Early Childhood Education schools. We accomplish observations in two schools, recorded in diary of field and photography. The results show positive and negative elements of the organizations and utilization of the physical spaces in the schools. Its mediator aspect in the children's learning can be unnoted for the teachers, if the reflexion about the quality doesn't be related to the goal of the children's activity. The mediation of the spaces in the children's learning need to be part of concerns of the teachers, managers, architects, engineers and focus of the public policies.
\end{abstract}

Keywords: Early childhood Education. Cultural Historical Theory. Play. Physical Space.

\title{
1 Introdução
}

A organização dos espaços em escolas de Educação Infantil é um aspecto importante da formação inicial e continuada de professores, uma vez que eles são potentes mediadores de aprendizagens das crianças e devem ser organizados intencionalmente para esse fim pelos envolvidos na educação da criança de 0 a 6 anos (incompletos).

Encontramos, comumente, vários problemas relacionados aos espaços físicos e materiais na Educação Infantil: espaços pequenos para o número de crianças, mal ventilados, com poucas oportunidades de vivências corporais, escassez de materiais, brinquedos dos parques em estado ruim de conservação etc., somadas a isso, as dificuldades de professores e gestores em organizar esses espaços para as atividades das crianças. Essa questão está diretamente relacionada à discussão das concepções de criança e infância que os adultos têm no momento de construir e organizar espaços nas escolas de Educação Infantil.

$\mathrm{Na}$ atualidade, a criança é concebida como um ser social, competente para relacionar-se com outras pessoas e apropriar-se da cultura (Parâmetros Nacionais de Qualidade para a Educação Infantil - BRASIL, 2006b). Essa concepção de criança opõe-se àquela cuja visão de infância é universal, única e natural. 
Este trabalho é parte da dissertação de mestrado da primeira autora, cuja intenção foi aprofundar a discussão sobre a qualidade dos espaços físicos das escolas de Educação Infantil, tendo como foco as brincadeiras e aprendizagens das crianças, de forma que esses espaços possam funcionar como mediadores dessas aprendizagens. Para tanto, a questão norteadora da pesquisa foi: de que maneira os espaços das escolas de Educação Infantil podem ser mediadores das aprendizagens e atividades de brincadeira das crianças? Os objetivos foram: a) identificar e discutir sobre a organização dos espaços internos e externos de escolas de Educação Infantil de um município do Estado de São Paulo; b) averiguar junto às escolas, quais desses espaços são destinados às brincadeiras das crianças; c) analisar como esses espaços são organizados para essas brincadeiras; d) identificar e analisar as possibilidades de mediação desses espaços nas aprendizagens e brincadeiras das crianças.

A pesquisa fundamentou-se na Teoria Histórico-Cultural, a qual defende a ideia de que a criança, desde bem pequena, é capaz de estabelecer relações com as outras pessoas e com as coisas, num processo em que percebe os significados, se apropria deles e atribui sentido a essas vivências, por intermédio da atividade principal de brincadeira (VYGOTSKI, 1995; LEONTIEV, 1978).

Leontiev (1978) argumenta que o desenvolvimento do psiquismo da criança é determinado pela forma como suas atividades se organizam nas condições concretas de sua vida e, cada uma dessas atividades, envolve um motivo e uma condição de necessidade. Essa necessidade se manifesta nos objetos, que não são neutros, impulsionando o indivíduo para a realização de determinadas ações.

Nessa perspectiva, os espaços das escolas de Educação Infantil também devem impulsionar o desenvolvimento das crianças e, quanto mais estimulante for a sua organização, maiores as probabilidades de aprendizagens. Então, a organização e o uso do espaço físico devem voltar-se às brincadeiras das crianças, que assumem papel imprescindível nos processos de aprendizagem e desenvolvimento infantis, já que são atividades que lhes proporcionam condições de selecionar, reproduzir e reelaborar situações que vivenciam no dia-a-dia, auxiliando-as a compreendê-las, a partir do repertório que tem naquele momento. 


\section{$2 \quad 0$ papel do espaço nas aprendizagens das crianças.}

Há muita controvérsia na definição do termo espaço, pois diferentes ambientes podem ser constituídos dentro de um mesmo espaço. Eles se definem por intermédio da relação estabelecida entre os indivíduos e deles com a organização do espaço. Para exemplificar a abrangência desse conceito, utilizamos algumas palavras de Sousa Lima (1989, p.30):

[...] não existem espaços vazios de significados... O espaço físico isolado do ambiente só existe na cabeça dos adultos para medi-lo, para vendê-lo, para guardá-lo. Para a criança existe o espaço-alegria, o espaço-medo, o espaço-proteção, o espaço-mistério, o espaçodescoberta, enfim, os espaços de liberdade ou de opressão.

Portanto, se o ambiente que está envolto em um espaço determinado tem valor simbólico para os indivíduos que utilizam esse espaço, e se esse valor simbólico é carregado de significações que, por meio de signos regulam e transformam as atitudes desses indivíduos, então esse espaço tem intencionalidade. Ao ser constituído e/ou organizado por alguém, sempre há subjacente a ele, uma intenção, assim como valores e concepções, que podem ser contrastantes ou não com os usuários desses espaços.

Isso não quer dizer que o adulto deva estruturar, demasiadamente, os espaços nos quais as crianças brincam, mas, que por intermédio da observação dessas brincadeiras, a professora possa introduzir as intervenções necessárias nos espaços mediante as necessidades das crianças.

Nesse sentido, Sousa Lima ressalta $(1989$, p. 72): “[...] É preciso deixar o espaço suficientemente pensado para estimular a curiosidade e a imaginação da criança, mas incompleto o bastante para que ela se aproprie e transforme esse espaço através da sua ação".

A discussão sobre os espaços nas escolas de Educação Infantil não pode e nem deve se resumir à sua metragem, insolação ou topografia. Ele deve ser entendido como ambiente, procurando conhecer e priorizar as necessidades e exigências das crianças nos momentos programados ou imprevistos, individuais ou coletivos, devendo ser continuamente planejado e reorganizado (SOUSA LIMA, 1989). 
Para Sousa Lima (1989, p. 72) um aspecto muito importante, que merece ressalva, é a concepção da própria criança na organização dos espaços e, nesse sentido, aponta: “[...] os espaços organizados e realizados pelas próprias crianças podem indicar algumas trilhas para o trabalho dos adultos".

O espaço deve, então, ser múltiplo e, ao mesmo tempo, proporcionar vivências individuais, deve conter os elementos que nos constituem como seres que sentem pelo cheiro, pelo toque, pelo gosto, pelo olhar e pela audição, pois a negligência no seu trato manterá essas sensações desconfortáveis ao indivíduo e deixará uma impressão negativa desse conjunto de relações que formam o ambiente.

\section{Metodologia.}

Coerentes com a Teoria Histórico-Cultural de Vigotsky não podemos conceber o espaço físico, nosso objeto de estudo nesta pesquisa, de uma forma isolada de todos os componentes que o constitui e nem das relações existentes nele.

Assim, a metodologia foi dividida em dois momentos: o primeiro relacionado aos participantes de um curso de extensão e o segundo, com dados de campo. No primeiro utilizamos uma amostra aleatória de 60 professores, dentre 300 participantes do curso e 27 diretoras de um total de 30 escolas de Educação Infantil. Três escolas não puderam participar por dificuldade de horário das diretoras em responder ao questionário. O segundo momento foi realizado em duas unidades escolares municipais denominadas de $A$ e $B$, cujos critérios foram: uma unidade com espaços pequenos e adaptados às atividades das crianças e outra grande, com diferentes espaços internos e externos, tais como: quadra de esportes, piscina, espaços gramados, calçados, em areia/terra e salas amplas e arejadas. Coletamos a autorização dos pais das crianças que participaram das observações, uma vez que registramos parte das observações por meio de fotos.

Para o primeiro momento, utilizamos dois questionários diferentes: um direcionado aos professores, que abrangeu as suas concepções sobre a importância das brincadeiras para as crianças na Educação Infantil; as dificuldades do trabalho dos professores em relação ao espaço físico para a realização de brincadeiras; a qualidade dos brinquedos do parque etc.; e outro às diretoras, sobre a estrutura física das escolas e as atividades realizadas 
nesses espaços. Para o segundo momento, realizamos observações de brincadeiras nos espaços das duas escolas, registradas em diário de campo e por meio de fotografias. Observamos duas atividades de brincadeira em cada escola: uma brincadeira dirigida pela professora e escolhida a seu critério e uma atividade livre das criancas, de preferência no parque. A observação foi realizada com crianças de 5 anos, pela disponibilidade das professoras em participar da pesquisa. Durante as atividades optamos por não utilizar um protocolo de observação; registramos e fotografamos algumas situações que nos chamaram a atenção em relação aos espaços físicos e à maneira como estes foram organizados para as atividades (discutidas na análise dos dados).

\section{$4 \quad$ Resultados: 0 espaço como mediador das atividades de brincadeira}

Agrupamos os dados coletados em uma única diretriz de análise - $O$ espaço como mediador das atividades de brincadeira -, subdividindo-a em quatro subdiretrizes, referenciadas aos objetivos da pesquisa: 1. Estrutura física - qualidade dos espaços $e$ aprendizagens das crianças; 2 . Os espaços externos e internos como mediadores dos tipos de atividade das crianças; 3. Espaço, brincadeira e brinquedos: a qualidade das aprendizagens das crianças e 4. As atividades dirigidas de brincadeiras, os espaços e a professora como mediadores das aprendizagens das crianças.

\subsection{Estrutura Física: qualidade dos espaços e aprendizagens das crianças}

A estrutura física das escolas de Educação Infantil pode ser mediadora de atividades de exploração para as crianças e incrementar suas aprendizagens, ou pode limitar e coibir tais aprendizagens, impedindo-as de se desenvolverem em níveis cada vez mais elevados. Além dos adultos, os objetos, as ferramentas, os signos, a linguagem, o tempo de duração das brincadeiras, as outras crianças, o próprio espaço físico e a maneira como ele é organizado são elementos mediadores nesses processos de aprendizagens e desenvolvimento infantis.

Um importante aspecto da estrutura física das escolas, levantado pelos professores, foi a relação entre o número de crianças em cada turma e o tamanho das salas de aula. A maioria deles (64\%) trabalha com cerca de 20 crianças entre 3 e 6 anos, que está de acordo com o documento Subsídios para Credenciamento e Funcionamento de Instituições de 
Educação Infantil (BRASIL, 1998). Porém, os professores vão além dessa relação e inserem o espaço das salas como importante elemento para qualificar as aprendizagens das crianças, como podemos observar em suas respostas:

[...] trabalho com 22 crianças de 5 anos. Para esta questão devemos pensar sempre no nosso espaço. O máximo por sala deveria ser 15/16 crianças, devido ao espaço físico.

[...] trabalho com 24 crianças. Pelo tamanho da minha sala eu acho que é um número alto, a sala é muito pequena, acredito que o número ideal seria 15 alunos por sala no máximo.

Segundo Elali (2002) a sala de aula, ainda, é considerada o ponto central da atividade educativa, embora esse conceito esteja em evolução. Ela precisa ter área suficiente para que as crianças desenvolvam múltiplas atividades, além de necessitar de boa iluminação natural e artificial, e de ser térmica, acústica e visualmente agradável.

Houve contradição entre as respostas das diretoras e das professoras sobre a qualidade dos espaços internos das escolas. Dos 60 questionários analisados, $50 \%$ dos professores consideram os espaços internos ruins; $33,3 \%$ de boa qualidade, $16,6 \%$ razoáveis e justificaram:

[...] A estrutura da sala não é adequada. Os vitrôs ficam muito altos e não têm ventilação.

[...] Nos dias quentes, faltam ventiladores, já que o telhado é forro plástico com brasilitão (sic), o chão fica inadequado $\mathrm{p} /$ os dias frios, já que é piso frio.

[...] na minha escola tem dois pavimentos, subir escadas para a merenda, descer para a sala de aula, subir para a Educação Física, descer para a sala, subir para o pátio, descer. Viu?!...

[...] Piso muito liso, terra, grama (dias chuvosos), móveis, ventilação não tem, espaço pequeno, frio (piso) etc.

Na maioria da avaliação das 27 diretoras a luminosidade das salas é boa e ótima: 8 $(29,6 \%)$ boa; 7 (25,9\%) ótima; 6 (22,2\%) regular; 2 (7,4\%) ruim; 2 (7,4\%) entre regular e boa, $2(7,4 \%)$ como regular e ruim, já que nessas unidades existem salas de diferentes tamanhos. Quanto à temperatura, em dias normais e em dias frios, a maioria das diretoras considera a 
temperatura boa (48,1\% e $66,6 \%$ respectivamente). Em dias quentes, a maioria considera a temperatura regular (37\%).

Segundo os Parâmetros Básicos de Infraestrutura para Instituições de Educação Infantil (BRASIL 2006a), além de proporcionarem ventilação e iluminação, as janelas devem estar ao alcance da criança, estabelecendo a integração e a visualização do ambiente externo e propiciar conceitos topológicos (dentro/fora, longe/perto etc.). As janelas podem ser exploradas nas atividades de brincadeiras e ser um elemento a mais na aprendizagem, por isso a importância de estarem na altura das crianças.

Barbosa e Horn (2001, p.76) também concordam que: "[...] as janelas devem servir de abertura ao mundo externo e, por esse motivo, serem bastante exploradas."

Carvalho (2008) também encontrou contradição na avaliação da qualidade de estrutura física nas escolas de Educação Infantil ao analisar desenhos que as crianças realizaram sobre o que elas menos gostavam na escola e a opinião dos professores sobre a escola. As crianças desenharam algumas barreiras arquitetônicas como escadas, caixas de areia altas, pilares etc., como elementos que dificultavam suas brincadeiras ou, locais onde haviam se machucado. Esses elementos passaram despercebidos pelos professores, já que avaliaram os espaços como bons.

Outro fator relevante é a observação da professora durante as atividades das crianças. Ela deve ouvir o que a criança tem a dizer e observá-la nos espaços para poder potencializar suas aprendizagens por meio da organização dos espaços que ela utiliza na escola. Nesse sentido, a próxima subdiretriz irá levantar a discussão sobre a utilização dos espaços externos e internos das unidades escolares como elementos mediadores dos tipos de atividades das crianças.

\subsection{Os espaços externos e internos como mediadores dos tipos de atividade das crianças}


A qualidade dos espaços tanto externos como internos nas escolas de Educação Infantil pode influenciar nos tipos de atividades que as crianças realizam e, principalmente, têm consequências na qualidade das aprendizagens e desenvolvimentos infantis.

Nas respostas das diretoras, o pátio coberto, por exemplo, é um dos espaços mais utilizados nas unidades que o possuem ( 21 escolas) para as atividades das crianças. Todas as escolas os utilizam para atividades de Movimento e atividades de Música/Teatro. 20 unidades os utilizam para a realização de atividades livres, 19 para atividades de brincadeiras/jogos/atividades dirigidas; 15 realizam atividades de Modelagem/Artes Plásticas e 14 atividades de ler/escrever/contar histórias.

Sager et al. (2003) demonstram em suas pesquisas que o pátio da escola deve ampliar a diversidade de espaço e oportunidades para diferentes tipos de brincadeiras, pois a criança, ao brincar em pátios definidos e com variedades de opções de atividades, concentra-se mais, o que pode contribuir para um ambiente mais tranquilo, sem agressões e conflitos, além disso, o pátio é muito importante, pois é onde têm lugar as interações com o grupo, por intermédio das brincadeiras.

Contudo, observamos que algumas escolas não têm essa qualidade esperada, e outras até apresentam pátios que dificultam as brincadeiras das crianças por meio de escadas (impossibilitando o acesso para crianças portadoras de necessidades especiais, por exemplo), espaços reduzidos, com pouquíssimos brinquedos e possibilidades de vivências. Na Escola A, por exemplo, registramos que o único espaço livre coberto para a realização de atividades é pequeno, com objetos velhos e botijões de gás no local, não havia muitos brinquedos, apenas um escorregador e dois pneus. Depois, foi introduzido um cesto com vários brinquedos, cujo aspecto positivo era estarem ao alcance das crianças. Entretanto, não basta disponibilizar brinquedos se a organização do espaço não potencializa as aprendizagens das crianças.

Das 27 escolas, 21 possuem parque, que, segundo as diretoras: 18 utilizam para atividades livres, seguidos de usos para outras atividades: ler, escrever,contar histórias (2); modelagem, artes plásticas (4); Educação Física, Movimento (12); brincadeiras,jogos,atividades dirigidas (15) e Música,Teatro (1). Outros espaços como gramados, áreas em areia, terra, horta, quadra de esportes e piscina não são muito 
explorados para as atividades de brincadeiras das crianças. Talvez, essa situação ocorra pela inadequação dos espaços externos para as atividades com as crianças, que, segundo as professoras, apresentam muitos problemas:

[...] parques pequenos e com brinquedos inadequados, quebrados e, principalmente, muito perigosos para as crianças.

[...] Os espaços têm que ser revistos. Escolas novas estão sem espaços, falta de planejamento desde a elaboração do projeto.

[...] Os espaços não foram construídos para crianças, foram arrumados.

[...] utilizo o pátio de baixo (dividido com as colegas), corredor (se não atrapalhar as colegas), muito pouca opção! (grifo nosso).

Das 27 escolas, 24 possuem salas de aula e 3 possuem salas temáticas. Nas 24 escolas, todas realizam nas salas de aula atividades de ler, escrever, contar, Em 23 havia atividades de modelagem, artes plásticas, brincadeiras, jogos, atividades dirigidas, atividades livres e atividades de música e teatro. Como podemos observar, a sala de aula é um espaço utilizado para praticamente todas as atividades das crianças em todas as unidades escolares.

Identificamos na Escola B que as carteiras são dispostas em filas como no Ensino Fundamental. A professora relatou que esse tipo de organização deve-se ao fato da sala ser utilizada no período noturno pela Educação de Jovens e Adultos. Ela considera que essa disposição não seja boa para as crianças, pois se torna escolarizante e gera certa dificuldade de acesso à elas pelas crianças, porque as carteiras são altas para a idade. Na visão da professora não há como organizar a sala de diferentes maneiras todos os dias.

Vygotski (1995) afirma que quando são impostas limitações físicas e culturais ao desenvolvimento da criança, estas se transformam em um obstáculo para o seu desenvolvimento e limitação cultural em todo esse processo.

A sala de leitura da Escola A não possuía carteiras, apenas uma mesa e duas cadeiras. Era uma sala com um pequeno tapete e almofadas no chão, onde as crianças se acomodavam, com estantes, livros, televisão, vídeo e computador. A lousa agregava trabalhos das crianças. Esse espaço, da maneira como estava organizado, tornava-se mais 
significativo para as crianças, ao se identificarem com ele e ao encontrarem as atividades elaboradas por elas, além de se movimentar com mais liberdade, em função da ausência de mesas e carteiras.

Barbosa e Horn (2001) entendem que uma organização adequada do espaço e dos materiais disponíveis na sala de aula é um fator decisivo na construção da autonomia intelectual e social da criança.

Os professores sugeriram algumas soluções para a melhoria dos espaços físicos, por exemplo: construção de escolas com espaços mais amplos adequados às vivências das crianças nesses espaços; troca de pisos, ampliação da iluminação artificial, pintura nova, melhora na arborização; instalação de prateleiras para livros nas salas; construção de espaços cobertos; rebaixamento de pia e vasos sanitários; local para contar histórias, assistir a TV, recreação nos dias de chuva; limpeza de áreas externas; manutenção dos brinquedos dos parques infantis, entre outras.

A estrutura física da escola pode ser um elemento mediador nas brincadeiras das crianças, porém torna-se necessário que esse elemento seja reconhecido como tal, tanto pela secretaria municipal de educação, quanto por diretores, professores, crianças e por que não dizer, pelas famílias. Todos os envolvidos têm o que falar e sabem analisar o que está inadequado. As soluções, porém, devem se encaminhar por meio do diálogo entre arquitetos, engenheiros e professores.

Essa subdiretriz apontou que os espaços internos e externos das escolas e a maneira como estão sendo utilizados pelos professores precisam ser repensados. A organização intencional dos espaços, a brincadeira e os brinquedos são elementos que podem atuar diretamente na qualidade das aprendizagens das crianças, o que discutimos na próxima subdiretriz de análise.

\subsection{Espaço, brincadeira e brinquedos: a qualidade das aprendizagens das crianças}


Se a qualidade dos espaços na estrutura física das escolas é importante para potencializar as aprendizagens, o que podemos argumentar sobre a qualidade das brincadeiras e brinquedos utilizados nesses espaços?

Mukhina (1996) afirma que o brinquedo é fundamental para o desenvolvimento da imaginação da criança pré-escolar e que, por meio dele e da brincadeira, a criança assimila normas de comportamento social e o utiliza como uma ferramenta de comunicação. Igualmente Elkonin (1998) argumenta que quanto mais ricas as experiências a que as crianças forem expostas, com diversificação e qualidade das brincadeiras, dos brinquedos e dos espaços, maior será sua inserção no mundo circundante e melhores serão suas aprendizagens.

A professora tem um papel fundamental nesse processo de mediação, pois é ela quem deve selecionar, organizar, disponibilizar intencionalmente os objetos e os brinquedos para as crianças, além de organizá-los no espaço, no qual a criança realizará suas brincadeiras. A presença de vários brinquedos não garante, porém, que as aprendizagens sejam de qualidade. Estes devem ser estimulantes para as crianças e, necessariamente, precisa haver a mediação da professora.

Nas respostas dos professores sobre os brinquedos que a escola possui obtivemos 66 respostas que revelam a escassez dos brinquedos: 19 (28,7\%) poucos brinquedos; 14 (21,2\%) muitos brinquedos; 13 (19,6\%) não possui brinquedos; 9 (13,6\%) possui brinquedos, mas a maioria é feita de materiais reciclados; $7(10,6 \%)$ brinquedos trazidos de casa e 4 (6,3\%) não responderam. Na opinião das professoras:

[...] são poucos, tal o número de crianças atendidas.

[...] Alguns poucos baldinhos e pazinhas, o que tem em maioria é sucata.

[...] Fizemos na escola a campanha do brinquedo usado, onde pedimos aos pais em reunião que mandassem brinquedos em boas condições de uso. Dividimos esses brinquedos entre as salas, junto aos que já tínhamos. 
[...] Não tem brinquedos, desde o ano passado que ficamos até sem os baldinhos.

Quanto ao acesso das crianças aos brinquedos, das 63 respostas obtidas, 36 (57,1\%) demonstram que os brinquedos ficam à disposição na sala de aula e a criança brinca livremente, $18(28,5 \%)$ as crianças têm acesso aos brinquedos em momentos préestabelecidos, ou seja, quando o professor oferece o brinquedo, 7 (11,1\%) não responderam, 1 (1,65\%) respondeu que as crianças tem acesso somente no parque e 1 $(1,65 \%)$ não tem brinquedos à disposição para as brincadeiras livres das crianças.

[...] Acesso livre, pois as estantes são baixas na altura delas, elas pegam, brincam e ajudam a guardar.

[...] Todos os brinquedos estão em caixas no chão ou, em cima de prateleiras baixas, dessa forma tudo está acessível à criança.

[...] Quando nós professores pegamos e entregamos a eles, o que ocorre sempre, pois não há brinquedos na sala.

[...] Os jogos ficam na sala. Mas não há um local baixo onde as crianças possam pegar à vontade. Os brinquedos ficam na sala de vídeo e as crianças podem pegar.

Durante as observações das Escolas A e B pudemos constatar a presença de brinquedos na Escola $\mathrm{A}$ à disposição das crianças no pátio coberto e no corredor de acesso às salas temáticas, guardados em grandes baldes. Os brinquedos dispostos na sala de brinquedos e na sala de jogos somente eram utilizados quando os professores levavam as crianças para esses espaços. Na sala de brinquedos os objetos ficavam ao alcance das crianças, porém na sala de jogos, alguns jogos ficavam em cima de uma pia alta, tornando-se inacessíveis para algumas crianças. Na Escola B presenciamos a utilização de alguns poucos brinquedos como baldes e pás para brincadeira na areia, somente no parque, disponibilizados para as crianças pela professora. Apesar de a Escola B apresentar melhores condições de espaços, os brinquedos são limitados quanto ao número e acesso das crianças.

A qualidade dos espaços internos e externos das escolas, potencialmente adequada às aprendizagens das crianças, devem agregar objetos mediadores, também potentes, para as brincadeiras de todas as crianças. 
Elkonin (1987) argumenta que os desejos infantis se alteram durante o processo da brincadeira, por isso a importância de o professor organizar, não somente os materiais utilizados durante a brincadeira, como também os espaços onde estas ocorrem, tornando-os diversos e atrativos, transmitindo, acima de tudo, um sentido para a brincadeira. Essa possibilidade de suporte aos desejos infantis faz da brincadeira um poderoso meio educativo, introduzindo temas importantes para a educação da criança.

Nesse sentido, Souza Lima (1989) concorda com Elkonin (1987) ao afirmar que o espaço não é apenas um lugar para a imaginação poética. Ele também deve ser fruto de conhecimentos objetivos, lugar de relações vitais e sociais concretas, determinado por elementos materiais que modificam sua natureza e qualidade. Daí a importância da presença de brinquedos diversificados e de qualidade ao alcance das crianças.

De acordo com Smirnov et al. (1960, p. 309) “[...] los productos de la imaginación, al mismo tiempo que tienen su origen en la realidad objetiva, se manifiestan de una manera material". Podemos inferir, então, que são necessários objetos (brinquedos) para que a imaginação possa se manifestar.

Quanto aos tipos, quantidade e qualidade dos parques infantis, observamos que existe grande diferença entre eles. Há parques com grande quantidade de brinquedos, todos adaptados à faixa etária e tamanho das crianças, e outros com brinquedos que não garantem segurança e nem possibilidades de aprendizagens diferenciadas pelas crianças.

Na observação da Escola A verificamos que o parque utilizado pela instituição não faz parte das dependências físicas da unidade; é um parque comunitário localizado em frente à escola, que as professoras utilizam para as brincadeiras, já que na unidade não existe espaço para a construção de um parque infantil. A área do parque não é cercada e não oferece proteção às crianças, pois os carros passam nas ruas frontal e lateral. Notamos, também, ausência total de arborização, ficando as crianças expostas ao sol todo o tempo em que permanecem nesse espaço. Já na Escola B, as crianças dispõem de um parque amplo, muito arborizado, com áreas sombreadas e com incidência de sol, sendo o parque cercado com grades revestidas por vegetação. 
Há escolas que apresentam parque com 06 caixas de areia e outras que não contam com nenhuma, pois não há espaço físico. Os brinquedos mais encontrados nos parques são escorregadores $(96,2 \%)$ e balanços $(85,1 \%)$. Em uma única escola há 09 gangorras, enquanto outras não possuem nenhuma. Não existem, em nenhuma das 27 unidades, brinquedos adaptados.

A qualidade envolve, também, o acesso das crianças com deficiências aos brinquedos e possibilidades de aprendizagens que eles proporcionam. Carvalho (2008) aponta em sua pesquisa algumas adaptações que devem ser feitas no parque infantil para essas crianças, por exemplo: a introdução de rotas acessíveis próximas aos brinquedos em locais sombreados para estacionar as cadeiras de rodas. Os brinquedos devem apresentar cores vibrantes e contrastantes, para que as crianças com baixa visão possam ter facilidade de localização e reconhecimento e, ainda, devem ser de plástico e sem quinas. Além disso, aponta que os brinquedos que podem envolver maior movimentação das crianças, como balanços e gangorras, devem ficar distantes daqueles que estimulam brincadeiras mais tranquilas, como caixa de areia e túnel.

A próxima subdiretriz discute como as professoras utilizam os espaços para atividades dirigidas de brincadeiras com as crianças e como utilizam o parque infantil para atividades de brincadeiras livres.

\subsection{As atividades dirigidas de brincadeiras, os espaços e a professora como mediadores das aprendizagens das crianças}

A importância do papel da professora como mediadora das brincadeiras e dos espaços configura-se na necessidade de seu discernimento sobre o que a criança precisa para aprender e desenvolver-se, e o que poderá dificultar esse processo na relação entre o tipo de brincadeira e a organização do espaço e dos diferentes objetos e brinquedos.

Analisamos alguns desses fatores nas atividades dirigidas pelas professoras e nas brincadeiras livres das crianças. A professora da Escola A optou por realizar a atividade dirigida na sala de leitura (sala temática), já que era uma atividade de contação de histórias. Como o espaço era muito pequeno, logo no início da atividade ocorreu um tumulto entre as crianças, pois aquelas que não conseguiam enxergar as figuras que a professora mostrava 
posicionaram-se à frente de outras. Havia outra sala no fundo desta que não possuía saída para o espaço externo, ou seja, quando as crianças da sala do fundo precisavam ir ao ambiente externo tinham, necessariamente, de passar pela sala da frente, atrapalhando a atividade de contação de história.

Se a professora tivesse a possibilidade de sair dessa sala para um local gramado, com árvores e objetos onde as crianças pudessem explorar o ambiente, contextualizando o que ouviram na história, seria um espaço de grande relevância para a utilização do faz de conta. A professora poderia utilizar esse espaço para tentar localizar as cores discriminadas na história, levantar hipóteses, entre outras possibilidades de utilizar o espaço como um elemento de mediação e entendê-lo também como tal.

Porém, nessa escola o espaço externo encontrado é um corredor estreito sem visão nenhuma para fora da unidade e um pátio coberto, pequeno, com pouquíssimos objetos. 0 único espaço externo mais amplo e com alguma possibilidade de ser utilizado dessa forma é o parque comunitário, localizado no lado externo à unidade escolar, sem segurança para as crianças.

Apesar de não ter sido totalmente um empecilho para o desenvolvimento da atividade, devido à resistência e persistência da professora e das crianças, esse caso nos mostra que essa mediação acontece, também, em condições não adequadas, mas poderiam ser infinitamente potencializadas se as condições adequadas tivessem sido priorizadas pelos gestores. Nesse sentido, as condições adversas geram dificuldades imediatas, cotidianamente, para a potencialização das aprendizagens das crianças, principalmente, para populações marginalizadas que têm dificultados os acessos à cultura, saúde e educação.

Já a professora da Escola B optou pela realização da atividade dirigida no espaço calçado, localizado no parque. Esses espaços externos são amplos e há uma grande quantidade de brinquedos, todos pintados com cores fortes, possuindo uma área bastante arborizada, com várias opções de pisos, como areia, grama, espaço calçado, proporcionando um grande número de espaços para a utilização de brincadeiras de movimento e, ainda, um grande pátio coberto. 
Apesar da qualidade dos espaços disponíveis para a realização dessa atividade foi interessante notar que a professora dividiu a turma em dois grupos de crianças. Enquanto um grupo participava da atividade, o outro ficou sentado, apenas olhando as outras crianças. O espaço, por ser amplo e arborizado, poderia ter sido utilizado para que todas as crianças participassem ao mesmo tempo da atividade. Entretanto, o procedimento de mediação da professora não foi amplo o suficiente para utilizar as possibilidades mediativas do espaço externo, com seus diferentes ambientes e estruturas. É necessário que ela o reconheça como tal e o utilize como um instrumento de mediação, também, em atividades de brincadeiras dirigidas. E podemos inverter essa relação: que a professora, também, possa ser a mediadora entre a criança e o espaço.

O aspecto mediador dos espaços das escolas nas aprendizagens das crianças pode passar despercebido para os professores, se ele não for relacionado à atividade que será desenvolvida e, principalmente, ao seu objetivo para a criança.

A melhoria da qualidade das estruturas físicas dos espaços, como aspecto mediador das aprendizagens das crianças, é importante na edificação de escolas de Educação Infantil. Entretanto, apenas as excelentes condições dos espaços não são suficientes para potencializar as aprendizagens e o desenvolvimento infantis. É fundamental, também, o papel mediador da professora, o seu olhar ampliado sobre os espaços em relação às atividades e o objetivo delas para a vida das crianças.

Ao analisarmos os dados coletados, nos deparamos com aspectos positivos e negativos dos espaços físicos, sua organização e utilização, nas escolas de Educação Infantil pesquisadas. Assim, a estrutura física, os tipos de brincadeiras e a mediação da professora exercem, juntos, influência no espaço, ao mesmo tempo em que esse espaço exerce influência sobre eles. É um movimento intrínseco, recíproco e contínuo, que não pode ser concebido de forma tangencial na Educação Infantil. Ele precisa ser o centro das preocupações conjuntas de professores, gestores, arquitetos, engenheiros e políticas públicas.

A organização intencional do espaço e dos brinquedos nas instituições de Educação Infantil deve permitir a participação de todos os atores envolvidos nesse processo, propiciando condições para a formação cultural das crianças. Partindo desse pressuposto, e 
de acordo com a Teoria Histórico-Cultural, que concebe a atividade como fundamental para o desenvolvimento dos indivíduos, as escolas de Educação Infantil e os professores devem propiciar motivos, necessidades e vivências que impulsionem as crianças a realizar as atividades, promovendo o maior número possível de aprendizagens de qualidade.

Nesse sentido, o espaço escolar deve ser organizado para tornar possíveis as inúmeras mediações, proporcionando à criança as mais ricas situações e vivências. A professora, de sua parte, ao conceber a criança como um ser ativo e social, deve estar atenta às especificidades das necessidades de aprendizagens das crianças e relacioná-las à organização dos espaços em que são realizadas as atividades. Assim, mais facilmente conseguirá apreender as maneiras pelas quais a criança se relaciona e se apropria dos espaços em que ocorrem as brincadeiras. Essas percepções que a professora vai desenvolvendo à medida que implementa as atividades, em contrapartida, fornecem-Ihe importantes pistas de como organizar, rearranjar e transformar os materiais, ambientes e espaços de maneira cada vez mais apropriada para as necessidades de aprendizagens de todas as crianças.

Segundo Elali (2002), assim como cada abordagem pedagógica persegue um ideal de homem e de mundo, na discussão do ambiente escolar deveria ser possível analisar as características do espaço face às abordagens pedagógicas. Embora tais elementos aparentem ter uma afinidade relativamente clara, na realidade não é tão direto. A configuração, estrutura e a estética da edificação é um reflexo das tendências pedagógicas vigentes e do fator social, como reflexo da realidade social e urbanística.

É fundamental que arquitetos e professores se conscientizem da importância de pensarem juntos a construção e a organização de espaços na Educação Infantil, para que estes sejam promotores de descobertas, desafios e aprendizagens das crianças. Porém, o mais importante é saberem a opinião dos maiores interessados nesse processo: as crianças. Elas podem e têm o que falar, basta que selecionemos os instrumentos adequados de coleta dessas informações e estejamos abertos para ouvir e interpretar o que as crianças dizem.

A cada dia que convivemos com as crianças percebemos que aquela concepção de que a criança vivia em um mundo infantil próprio, e que não precisava saber sobre o mundo 
adulto, é extremamente falsa. A criança faz análises importantes sobre o que vivencia a partir do repertório que ela tem para poder interpretar.

Os adultos, na correria do cotidiano, não têm tempo de ouvir e entender o que a criança diz. É importante que as professoras e demais envolvidos com a educação da criança compreendam o seu papel, também como mediadores interpretativos dessas análises das crianças sobre os conhecimentos de que estão se apropriando nas relações com o mundo.

\section{Referências}

BARBOSA, M.C.S.; HORN, M.G.S. Organização do espaço e do tempo na Escola Infantil. In: CRAIDY,C.M.; KAERCHER, G.E.P.S. (Orgs.). Educação Infantil - Pra que te quero? Porto Alegre: Artmed, 2001.

BRASIL. Ministério da Educação. Secretaria da Educação Básica. Parâmetros básicos de infraestrutura para instituições de educação infantil. Brasília: MEC, SEB, 2006a.

BRASIL. Ministério da Educação. Secretaria da Educação Básica. Parâmetros Nacionais de qualidade para a Educação Infantil. Brasília: MEC, Volume 1, 2006b. 57p

BRASIL. Ministério da Educação. Secretaria da Educação Básica. Parâmetros Nacionais de qualidade para a Educação Infantil. Brasília: MEC, Volume 2, 2006b.

BRASIL. Ministério da Educação e do Desporto. Secretaria de Educação Fundamental. Subsídios para Credenciamento e Funcionamento de Instituições de Educação Infantil. Brasília, DF: MEC/SEF, 1998. 
CARVALHO, T. C. P. A arquitetura escolar inclusiva: espaços para a educação Infantil. Tese (Doutorado na Área de Concentração em Arquitetura, Urbanismo e Tecnologia) Universidade de São Paulo, São Paulo, 2008, 340f.

ELALI, G. A. Ambientes para educação infantil: um quebra-cabeça? Contribuições metodológicas na avaliação pós-ocupação de edificações e na elaboração de diretrizes para projetos arquitetônicos na área. Tese (Doutorado em Estruturas Ambientais Urbanas) Faculdade de Arquitetura e Urbanismo, Universidade de São Paulo, São Paulo, 2002. Volume 1, 305f.

ELKONIN, D. B. Psicologia do jogo. São Paulo: Martins Fontes, 1998.

ELKONIN, D. B. Problemas psicologicos del juego en la edad preescolar. In: La Psicologia Evolutiva y Pedagogica en la URSS: Antologia. Moscou: Editorial Progresso, 1987. P. 83-102.

LEONTIEV, A. N. O desenvolvimento do psiquismo. Lisboa: Livros Horizonte, 1978.

MUKHINA, V. Psicologia da idade pré-escolar. São Paulo: Martins Fontes, 1996.

SAGER, F; SPERB, T.M.; ROAZZI, A.; MARTINS, F.M. Avaliação da interação de crianças em pátios de escolas infantis: uma abordagem de Psicologia Ambiental. Psicologia, Reflexão e Crítica, Porto Alegre, RS, v.16, no 1, p.203-215, 2003. 
SMIRNOV, A.; LEONTIEV, A.; RUBINSHTEIN, S.; TIEPLOV, B. Psicologia. México: Editorial Grijalbo, 1960.

SOUSA LIMA, M. A cidade e a criança. São Paulo: Editora Nobel, 1989.

VYGOTSKI, L. S. Obras Escogidas. Tomo III. Madrid: Visor Distribuciones S.A., 1995.

Enviado em Agosto/2012

Aprovado em Junho/2013 